\title{
The Influence of Behavioural Finance Factors and the Moderating Effects of Contextual and Demographic Factors on Individual Investor's Investment Performance
}

\author{
Tuan Derwyn Hamidon ${ }^{1} \&$ Sampath Kehelwalatenna ${ }^{2}$ \\ ${ }^{1}$ School of Management, BCAS Campus, Mount Lavinia, Sri Lanka \\ ${ }^{2}$ Department of Accounting, Faculty of Management and Finance, University of Colombo, Colombo 0003, Sri Lanka \\ Correspondence: Sampath Kehelwalatenna, Department of Accounting, Faculty of Management and Finance, \\ University of Colombo, Colombo 0003, Sri Lanka.
}

Received: August 1, 2020

Accepted: August 24, 2020

Online Published: August 25, 2020

doi:10.5430/afr.v9n3p101

URL: https://doi.org/10.5430/afr.v9n3p101

\begin{abstract}
Individual investors trading on the Colombo Stock Exchange (CSE), Sri Lanka, behave irrationally despite objective finance models available for them to refer in making rational decisions. Therefore, this paper examines the irrationality by testing whether behavioural finance factors (BF), stock broker's recommendations (SBR) as a contextual factor, and individual investor's existing knowledge of the stock market (EK) as a demographic factor affect individual investor's investment performance (IP). Heuristic behaviour, prospect behaviour and market factors were conceptualised as independent variables of the study whereas SBR and EK act as moderators on the relationship between BF and IP. Data of 221 individual investors of CSE during first half of 2019 were analyzed using structural models to draw empirical evidence to test hypotheses of the study. Results of the study reveal that market information and past stock trends as market factors have a significant bearing on investment decision making, which ultimately affect IP, while the aggregate effect of BF upholds a significant impact on IP. The results expose some novel findings such as: investors receive inferior financial returns when imitating other investors' trading behaviour whilst trading on SBR; receive lower returns once trading on market factors whilst resuming SBR; and receive mediocre returns when EK is affirmative whilst following other investors' decisions; and suffer losses when trading on market factors whilst exploiting EK. The findings imply that the stock brokers should not merely consider the output of objective finance models, but market wide herding, market manipulations, market factors and EK in investment recommendations.
\end{abstract}

Keywords: behavioural factors, individual investors, investment performance, Colombo Stock Exchange, Sri Lanka

\section{Introduction}

The stock market is a popular and a more effective channel for trade unlike any other type of investment due to its high liquidity (Jaswani, 2008). According to Croushore (2006), most of the investors purchase stocks because of their desire to take decisions as owners. Benefits for such investors are numerous while the downside risk for them is limited to invested capital. Efficient Market Hypothesis presumes that markets are rational and efficient (Fama, 1970). In contrast, behavioural finance contemplates that financial markets occasionally do not possess informational efficiency (Ritter, 2003). Generally, traditional finance theories: Capital Asset Pricing Model (Sharpe, 1964; Lintner, 1965; Black, 1972), Dividend Discount Model (Gordon \& Shapiro,1956; Gordon, 1959; Gordon, 1962) and Markowitz Mean-variance Portfolio Theory (Markowitz, 1959) are backed by logical reasoning. However, this logic is questioned by many other scholars (Kahneman \& Tversky, 1974; Kahneman \& Tversky, 1979; Waweru, Munyoki \& Uliana, 2008; Gounaris \& Prout, 2009) as such logic is found to be less realistic. Thereby, the quest to understand what finance truly is has to move beyond conventional finance theories.

As far as the theoretical framework is concerned, contextual factors (CF), including SBR have been identified as influencing the individual investor's investment decisions and investment performance (Nagy \& Obenberger, 1994; Chandra \& Kumar, 2011; Sultana \& Pardhasaradhi, 2012; Menike, Dunusinghe \& Ranasinghe, 2015). Numerous scholars have studied various demographic factors (DF), namely: age, gender, income, education (knowledge) and experience, and found them to have an influence on individual investor's investment behaviour (Warren, Stevens \& McConkey, 1990; Amiri, Razavizade \& Vahidi, 2011; Kabra, Mishra \& Dash, 2011). However, to the best of the 
researchers' knowledge, both SBR as a CF and EK as a DF have not been incorporated together in one study to examine their moderating effects on IP.

There are few studies conducted on IP using data from Sri Lanka. In this respect, Sewwandi (2016) examined market wide herding and found no herding activity in both up and down-market phases. In contrast Menike et al. (2015) found evidence for the existence of herding behaviour based on their study of 164 individual investors. Additionally, Kengatharan \& Kengatharan (2014) concluded that only choice of stock as part of herding, overconfidence and anchoring have an influence on IP. In the face of such inconsistent findings in Menike et al. (2015) and Sewwandi (2016) conducted in alike period, and available studies (i.e. Kengatharan \& Kengatharan, 2014; Menike et al., 2015; Sewwandi, 2016) not adequately address the phenomenon of behavioural finance (BF) and their impact on IP, a pivotal requirement for conducting further research arises. Accordingly, the present study attempts to determine the impact of BF on IP, and to examine the extent of SBR as a CF and EK as a DF moderate the relationship between BF and IP using the data of Sri Lankan context. In achieving the above objective, the paper develops a conceptual framework to capture BF, SBR and EK that affect IP. IP predictors: BF (Kahneman \& Tversky, 1974; Kahneman \& Tversky, 1979; Waweru et al., 2008) and moderators: SBR as a CF (Nagy \& Obenberger, 1994) and EK as a DF (Warren et al., 1990) provide a theoretical foundation for the proposed conceptual framework. The present study primarily adds evidence to the literature on the relationship between DF and IP of Sri Lanka. Moreover, the study attempts to add new attributes to the existing body of knowledge in BF by examining the role of SBR and EK as moderating variables on the relationship between DF and IP.

The remainder of this paper is structured as follows. The succeeding section critically reviews relevant literature for the study and presents the hypotheses that are developed according to the proposed conceptual framework. Section three of the paper presents the methodology while Section four analyses the data. Section five presents the discussion and section six concludes the paper.

\section{Literature Review}

Investors' investment decisions are, basically, three fold: buy, sell or hold. Focus of this paper is on buying and selling decisions of individual investors. Barber and Odean (1999) offered several insights on preferable stocks that individual investors should buy. It is the general understanding that investors would buy stocks if they think that prices would move upwards in the future, so that they could gain from the positive difference between the purchase price and the selling price. Thereby, as opposed to selling decisions that mainly prioritise winning stocks, as far as buying decisions are concerned, it can be seen that they are related to both prior winning stocks as well as losing stocks. Investors decrease selling decisions of assets that would incur losses in comparison to the initial purchasing price, a trend called the 'disposition effect' (Shefrin \& Statman, 1985). To go with a selling decision, investors would want to make profits by selling the stock at a higher price than they bought it. According to Odean (1998) it is not rational to conclude that investors logically sell winning stocks since they can anticipate such stocks' poor performance.

Accordingly, in the context of behavioural finance, investor's behaviour influences both buying and selling decisions at different levels. Moreover, it also influences general financial returns of the market as well as investment performance of individual investors (Luong \& Ha, 2011). Some adversaries of behavioural finance criticise that the unsatisfactory performance of irrational investors can lure them away from the stock market. On the contrary, some scholars and professionals believe that overconfident investors who exhibit extreme trading behaviour could benefit with greater financial returns (Anderson, Henker \& Owen, 2005). Anderson et al. (2005) concluded that individual investors who engage in a large amount of transactions might receive greater returns than individuals who engage in fewer transactions.

Behavioural finance theories contemplate how numerous psychological traits influence how individuals or groups play their role as investors, analysts and portfolio managers. Furthermore, many researchers note that traditional finance theories are incomplete as they fail to explain individual investor behaviour. However, scholars who studied behavioural finance do not completely ignore traditional finance models, but rather point out that such models can be held true within specific boundaries explaining rational behaviour and profit maximization (Reilly \& Brown, 2009). Behavioural finance theories attempt to understand how feelings, emotions and cognitive errors of humans could affect the behaviour of individual investors. These theories are based on the psychological aspects of human decision making, and suggest how such decisions are subject to several cognitive deceptions. These behavioural biases tend to be subjective, meaning that they vary from one person to another because of various mental illusions (Ritter, 2003). According to the study carried out by Waweru et al. (2008), such illusions can be sub-divided into two: the deceptions caused by the heuristic decision process and those upheld in prospect theory (PT) as deceptions deeply 
rooted in the adoption of mental frames.

It is believed that the higher the investment performance of individuals, the higher would be their satisfaction. Therefore, higher satisfaction leads to more trading in the stock market as it stabilises both the primary and secondary markets (Rashid \& Nishat, 2009). Additionally, large volumes of trading will enhance liquidity in the market, as the market is objectively active and productive. On the other hand, a market with higher liquidity will open up supplementary opportunities for firms, as they are now able to raise more capital from the financial market.

As per the argument of Ritter (2003), heuristics are defined as the rules of thumb which make decision making easier especially in complex and uncertain environments. Heuristics help to reduce complexity of assessing probabilities by way of predicting values to simpler judgments (Kahneman \& Tversky, 1974). Thereby, individuals might be prone to taking investment decisions purely based on their judgment or sometimes known as best guess. It is believed that simplification may lead to more effective decision making since every investor may not possess high financial acumen. Therefore, rules of thumb are likely to play a huge role in an individual's decision making process, which ultimately may save cost and time on the part of such individual investors whom rely on such rules of thumb. Simmons, LeBoeuf and Nelson (2002) found six behavioural biases stemming from Heuristic Theory namely: herd behaviour, overconfidence, representativeness, self-attribution, belief perseverance and anchoring.

Herd behaviour, stemming from heuristics, is where individuals are led to imitate the majority of individuals' decision-making behaviour, by following their decisions. People are believed to be profound social beings, depending on each other for survival. It is argued that such people make decisions especially when they feel insecure or vulnerable. Such that, they observe closely what others do and then imitate (Gounaris \& Prout, 2009). The relevance of herding as part of the decision-making behaviour of the individuals is highly misleading in the context of investment decisions. According to Devenow et al. (1996), herd behaviour, when taken an irrational approach results in investors follow each other thoughtlessly forgoing rational analysis, meaning all the fundamentals where in which finance is based upon is omitted. They further emphasise that herding can take both a rational and irrational path, where rational herding is information based and irrational herding reflects investors with inadequate access to information and improper evaluation of risk-return profiles following other investors blindly. Interestingly, irrational herding leads to market inefficiencies driving asset prices away from their intrinsic values, eventually triggering asset mispricing, which is where the problems take place (Froot, Scharfstein \& Stein, 1992; Hirshleifer, Subrahmanyam \& Titman, 1994; Hwang \& Salmon, 2004; Hung, Lu \& Lee, 2010).

When people overestimate the reliability of their knowledge and skills, it is the demonstration of overconfidence (DeBondt \& Thaler, 1995; Hvide, 2002). As argued by Taylor and Brown (1988) overconfidence is important for investors who heavily rely on their skills to achieve a better than average investment performance. The authors of the present study believe that some investors, at least, are likely to be carried away by their over-reliance on their own understanding about the stocks and the market when making investment related decisions. On the other hand, overconfidence may lead to improved investment performance, as the decisions taken by an overly confident individual may stand strong and persistent irrespective of the sentiment created by the other market participants.

Expected Utility Theory (EUT) explains about investors' rational expectations by emphasising the analysis of decision making under risk taking, a rational choice of economic behaviour. In contrast, PT describes some states of mind affecting an individual's decision-making process including regret aversion, loss aversion and mental accounting (Waweru et al., 2008). Thereby, it is quite evident that PT and EUT take a dissimilar stance when explaining about investor behaviour. According to Filbeck, Hatfield and Horvath (2005), PT is a phenomenon favouring the subjective decision making process of individuals based on their own value system while EUT is about objective decision making by individuals based on logic or rationale. Moreover, during uncertain financial market conditions investors take decisions based on the potential value of losses or gains rather than the ultimate outcome (Kahneman \& Tversky, 1979).

PT adopts cognitive psychological techniques to argue abundant documented variances in economic decision making from neo-classical theory. Moreover, Kahneman and Tversky (1979) document that individuals are traditionally risk lovers for losses. The utility function is a concave for gains as people display satisfaction when they gain, but twice the gain does not necessarily result in twice the satisfaction from the gain. The utility function is a factor for loss when people experience discomfort when they lose, but twice the loss does not mean twice the discomfort. Loss aversion refers to the inconsistency in the level of mental penalty people have from similar size loss or gain (Barberis $\&$ Huang, 2001). This refers to a mental state that investors at the time of evaluating their investment performance, will be more worried after they have suffered a loss from trading stocks rather than how much happy they are after making a profit from trading stocks. According to Tversky and Kahneman (1992) investors are most likely to be risk 
averse in the "profitable zone" and risk seeking in the 'losing zone'. There is evidence showing that people are more distressed at the prospect of losses than they are pleased by equivalent gains (Barberis \& Thaler, 2003).

According to Sharpe (1964), early studies have advocated the existence of a significant positive relationship between security beta and expected returns which directly supports the CAPM. However, the observation in the real world is that the prices do not always reflect the CAPM theory. This indicates that behavioural biases of investors reflect different prices which cannot be explained using traditional finance theories. Accordingly, Waweru et al. (2008) found that market factors have an impact on investors' decision making. Barber and Odean (1999) stated that investors prefer buying to sell stocks that experience higher price changes during the past two years. Change in stock price in this context can be considered as an attention-grabbing occurrence in the market by investors.

Many scholars have identified several demographic factors in the discipline of behavioural finance. Warren et al. (1990), Kabra et al. (2010), Amiri et al. (2011) and Ponnamperuma (2013) studied about various demographic factors namely age, gender, income, education and experience to have an influence on individual investors' investment decisions. Furthermore, Lin (2011) established that four personal characteristics and three demographic features have a significant influence on three behavioural partialities with respect to investments. Eagly and Carli (1981) acknowledged that females are more disposed to exhibit herd behaviour than males. Menkhoff, Schmidt and Brozynski (2006) found that individuals who do not have a college degree are more pertinent to herding.

\section{Methodology}

\subsection{Hypotheses and Conceptual Framework}

Odean (1999) offers several identifications about preferable stocks that individual investors would like to buy. Shefrin and Statman (1985) state that investors decrease the selling decisions of assets that get a loss in comparison to the initial purchasing price which is known as a trend called the 'disposition effect'. Anderson et al. (2005) conclude that individual investors who make higher amount of transactions may result greater returns than individuals with fewer transactions may. Therefore, this paper attempts to examine the impact of individual investors' investment decisions on IP. According to Luong and Ha (2011) stock trading (investment) decisions, selling and buying stocks are linked to other decisions as well as they have a greater impact on IP. Therefore, this paper proposes that heuristic factors, prospect theory, market factors, contextual factors and demographic factors have an impact on IP.

Heuristics simply could be described as rules of thumb which makes the investors life easier in terms of making investment decisions where there is major complexity and uncertainty in the investment environment (Ritter, 2003). As per Kahneman and Tversky (1974) representativeness, availability bias and anchoring stands out as key heuristics. The findings of Menike et al. (2015) revealed that confident investors trading in the CSE are more likely to use their skills and knowledge in certain situations to increase their investment performance. Furthermore, the individual investors overestimate their ability to produce information with the help of accessible data that others neglect, will make cognitive errors in predicting future prices and they are more likely to be overconfident about the facts they create ignoring the publicly available information. Supporting this finding Kim and Nofsinger (2008) stated that overconfident investors are more likely to sell their winning stocks and holding their losing stocks, which can affect adversely on their investment performance.

According to studies done by Froot et al. (1992), Hirshleifer et al. (1994), Hwang and Salmon (2004) and Hung et al. (2010), irrational herding leads to market inefficiencies driving asset prices away from their intrinsic values, eventually triggering asset mispricing, illustrating herding effect with regards to investment. Herding refers to the behavioural presence of herding activity and presumed to cause inefficiency in market because in security markets investors base their investment decisions on others' decisions of trading stocks. Herding behaviour is one branch of behavioural finance, and of course, herding is a common phenomenon in behavioural finance attracting the interest of many researchers (See Bikhchandani et al., 1992; Choe et al., 1998; Jones et al., 1999; Wermers, 1999; Bowe \& Domuta, 2004; Chen \& Hong, 2006; Uchida \& Nakagawa, 2007; Lin et al., 2007; Demirer et al., 2010). Waweru et al. (2008) found that masses' buying, selling, choice of stock, length of time to hold stock, and volume of stock to trade can impact on investment decision. Menike et al. (2015) found strong evidence of the existence of herding effect among the individual investors that positively effect on IP at the CSE. Moreover, their findings provide evidence that individual investors at the CSE base their investment decisions on the masses' decisions of buying or selling stocks and they react quickly to others' investment decisions expecting higher returns on investments. Corresponding to the discussion carried out thus far, the first hypothesis of the study is:

$\mathrm{H}_{1}$ : Heuristic factors have a significant impact on an individual investor's investment performance on the CSE. 
According to Filbeck et al. (2005), EUT focuses on investors' rational expectations by emphasising the analysis of decision making under risk taking and rational choice of economic behaviour. On the contrary, PT refers to a state of decision making that is subjective where such decision making is influenced by investors' value system. Kahneman and Tversky (1979) argued that the people have an irrational propensity to be less willing to gamble with profits than with losses. Adding to this, Waweru et al. (2008) stated that regret aversion, loss aversion and mental accounting contribute to the states of mind of an individual ultimately affecting investment decisions taken by such individuals. Menike et al. (2015) found that loss aversion carries a negative impact on the IP at the CSE. Further studies by Barberis and Huang (2001) and Barberis and Thaler (2003) provided strong support to the findings of Menike et al. (2015) who argue that investors are more distressed at the prospect of losses than they are pleased by equivalent gains. Accordingly, the second hypothesis of the study is presented as follows:

$\mathrm{H}_{2}$ : Loss aversion as a cognitive bias under prospect theory has a significant impact on an individual investor's investment performance on the CSE.

Market factors could impede investors' decisions by having an impact upon their behaviour. They are referred to changes in market information, fundamentals of the underlying stock and intrinsic values stock price. Waweru et al. (2008), identified price changes, market information, past trends of stocks, customer preference, over-reaction to price changes, and fundamentals of underlying stocks to be the market factors in way of behavioural finance factors. Consequently, the third hypothesis of the study is offered as follows:

$\mathrm{H}_{3}$ : Market factors have a significant impact on individual investors' investment performance on the CSE.

Heuristic factors, prospect theory and market factors are branches of the dimension, behavioural finance factors Ritter (2003), Waweru et al. (2008). To assess the cumulative effect of behavioural finance factors, the association between BF and IP was hypothesised as being positive. Accordingly, the alternative form of the fourth hypothesis is presented as follows:

$\mathrm{H}_{4}$ : Behavioural finance factors collectively have a significant positive impact on individual investors' investment performance on the CSE.

Menike et al. (2015), Chandra and Kumar (2011), Nagy and Obenberger (1994), Obamuyi (2013), Sultana and Pardhasaradhi (2012), and Ponnamperuma (2013) identified accounting and financial information, price fluctuations of stocks and stock broker's recommendations as contextual factors affecting individual investors' investment decision making. Menike et al. (2015) also found that stock broker's opinion (recommendations) has the highest impact among the contextual factors. Hence, the fifth hypothesis of the study is stated below:

$\mathrm{H}_{5 \mathrm{a}}$ : Stock broker's recommendations, as a contextual factor, strongly moderates the relationship between heuristic factors and an individual investor's investment performance on the CSE.

$\mathrm{H}_{5 b}$ : Stock broker's recommendations, as a contextual factor, strongly moderates the relationship between market factors and an individual investor's investment performance on the CSE.

Warren et al. (1990), Kabra et al. (2010), Amiri et al. (2011), and Ponnamperuma (2013) studied about numerous demographic factors such as age, gender, income, education (knowledge) and experience have an influence on individual investors' investment behaviour. Barberis and Thaler (2003), Ritter (2003), Waweru et al. (2008), Barberis and Huang (2001), Gervais, Simon and Odean (2001a), Luong and Ha (2011), Allen and Evans (2005), Rockenbach (2004), Kengatharan and Kengatharan (2014), Kumar and Lee (2006), Baker and Wurgler (2007) have found that there are various psychological factors - heuristics, prospect, herd behaviour - contextual factors, market factors and demographic factors affect the individual investors' investment decisions and IP.

According to Ponnamperuma (2013), EK is considered as a significant factor by individual investors when making their investment decisions that impact IP. Moreover, as evidenced by studies carried out on the United Arab Emirates Stock Market, investors who possess a higher level of education, demonstrated signs of active involvement in their investing decision making leading to a significant relationship between financial investment literacy and investment decisions influencing IP (Vitt et al., 2000; Cude et al., 2006; Al-Tamimi \& Kalli, 2009). Accordingly, the sixth hypothesis of the study stands as follows:

$\mathrm{H}_{6 \mathrm{a}}$ : An individual investor's existing knowledge of the stock market, as a demographic factor, strongly moderates the relationship between heuristic factors and an individual investor's investment performance on the CSE.

$\mathrm{H}_{6 \mathrm{~b}}$ : An individual investor's existing knowledge of the stock market, as a demographic factor, strongly moderates the relationship between market factors and an individual investor's investment performance on the CSE. 
The scope of the present paper is limited to studying the moderating effects of stock broker's recommendations, as a contextual factor and an individual investor's existing knowledge of the stock market, as a demographic factor on the relationship between heuristic factors and an individual investor's investment performance and on the relationship between market factors and an individual investor's investment performance. According to the aforementioned hypotheses developed based on literature, the conceptual framework for the current study is presented under figure 1 :

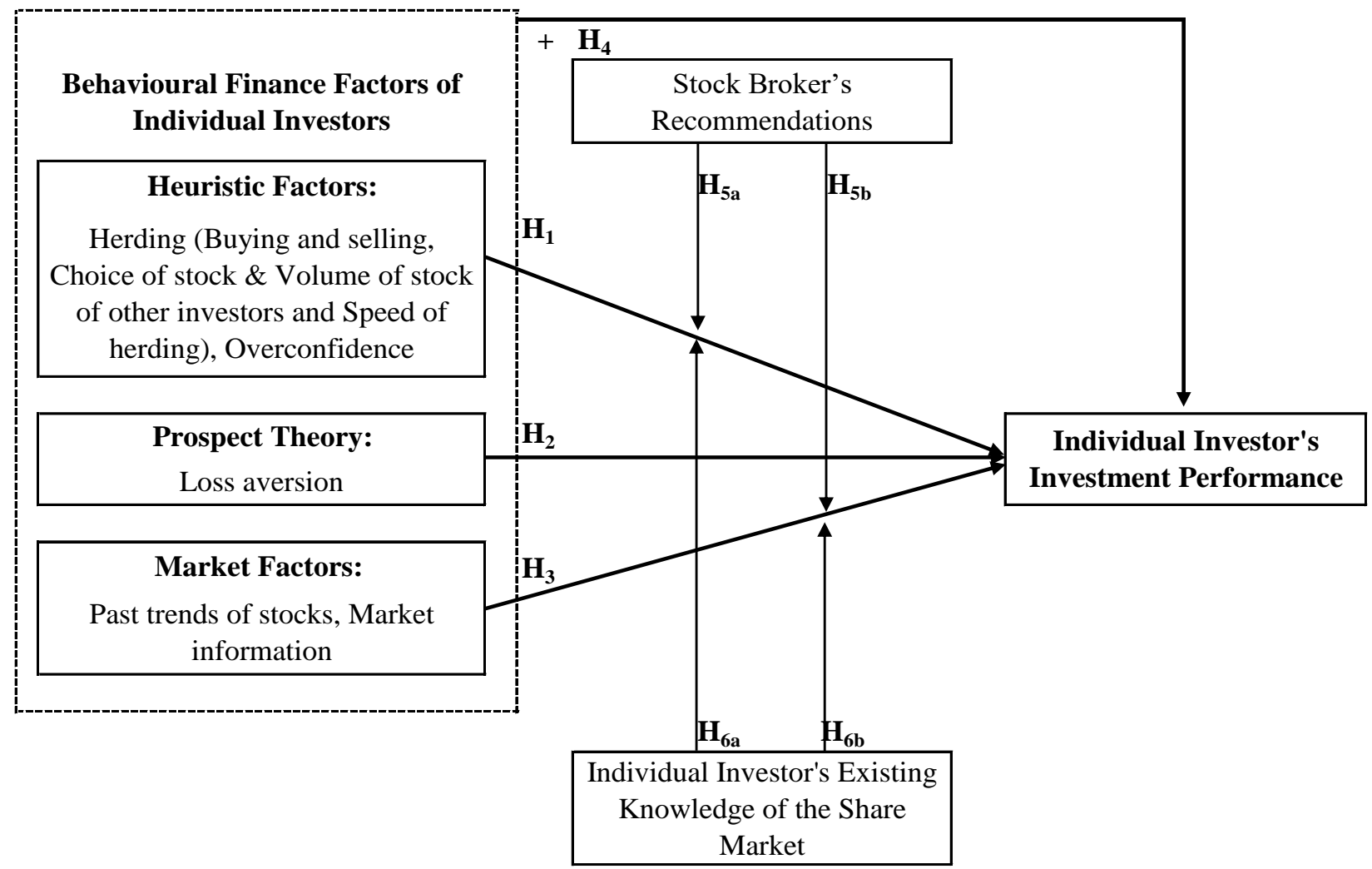

Figure 1. Conceptual framework

\subsection{Key Definition of Variables}

Herding Mentality/ Effect (Herd Behaviour);

According to Devenow et al. (1996), herd behaviour, when taken an irrational approach results in investors following each other thoughtlessly forgoing rational analysis, meaning all the fundamentals where in which finance is based upon is omitted.

Heuristic Theory;

According to Ritter (2003), Heuristics are defined as the rules of thumb, which makes decision making easier, especially in complex and uncertain environments.

Prospect Theory;

Prospect Theory describes some states of mind affecting an individual's decision-making processes including Regret aversion, Loss aversion and Mental accounting (Waweru et al., 2008).

\section{Market Factors;}

Waweru et al. (2008) identified the factors of market that have impact on investors' decision making: Price changes, market information, past trends of stocks, customer preference, over-reaction to price changes, and fundamentals of underlying stocks.

Contextual Factors;

Chandra and Kumar (2011) found (i) Market share and reputation of the firm, (ii) Accounting and financial 
information, (iii) Publicly available information through various media, (iv) Advocate recommendations including that of brokers, family and friends, and (v) Personal financial need are found out to be contextual factors that could possibly impacting individual investors' investment behaviour.

Demographic Factors;

Pavani and Anirudh (2010) examined that the demographics and psychographics of the investor, considering the parameters like age, gender and income groups and also some psychological parameters that will attract the investor towards that particular investment.

Individual Investor's Investment Performance;

Anderson, Henker and Owen (2005) concluded that individual investors who make higher amount of transactions might result greater returns than individuals with fewer transactions may.

\subsection{Sample and Data}

Unit of analysis of this study is individual investors who have invested in the CSE. In drawing a sample from a population of the entirety of individual investors trading on the CSE, 300 questionnaires were distributed among individual investors on convenient sampling basis. Out of the distributed questionnaires 221 completed questionnaires were returned ensuring a response rate of 74 percent.

\section{Data Analysis}

To assess the reliability of the measurement scales of this study, Cronbach's coefficient alpha developed by Cronbach (1946) was used. The Cronbach's alpha (CA) value of the survey was 0.803 , indicating a high degree of reliability and the researchers were able to proceed with the analysis (Hair et al., 2010). Successful completion of the pilot study led to the entry of data collected into IBM SPSS (version 20.0). In preparing for the analysis, data were cleaned by removing the missing responses (Nardi, 2005) and extreme outliers (Tukey, 1977; Malhotra, 1999) and inspecting for data entry errors. There were neither missing values nor data entry errors; nonetheless, 12 data points (observations) were identified as extreme outliers and were eliminated to enhance the accuracy of the study. As such, after applying these data cleaning techniques, the 209 remaining data points were held to be clean and were ready for further analyses. After treatment for any data entry errors, missing values and outliers, to eliminate any measurement errors and false internal consistencies, statistically called Common Method Biases, henceforth referred as CMB (Spector, 1987; Nunnally, 1978; Bagozzi \& Yi, 1991) and Common Method Variance, henceforth referred as CMV (Chang, Witteloostuijn \& Eden, 2010) respectively, Harman's Single-factor Test was executed. Accordingly, Exploratory Factor Analysis (EFA) results revealed five factors, which were greater than the number of factors employed in the actual study, which are four factors. The first factor (i.e. BF) explained approximately 21 percent of the variance of the sample, and that is comfortably below the criterion of 50 percent. All of the factors employed in the study, namely: BF, SBR, EK and IP, collectively, could explain more than 78 percent of the variance of the sample, which is more than the criterion of 50 percent. Therefore, it can be concluded that the common method bias of this study has been controlled after the application of the statistical remedy. One-way Analysis of Variance (ANOVA) test under SPSS was utilised to assess whether the study is free from non-response bias. The results of the study concluded that this study is not influenced by non-response bias.

Subsequently, the data were tested for multivariate assumptions such as: linearity, homoscedasticity and multicollinearity, and all variables satisfied the multivariate assumptions. Kaiser-Meyer-Olkin (KMO) test was adopted to measure the sample adequacy of the study. KMO results revealed that sample adequacy of BF was 0.755 that is in between 0.70 and 0.79 , meaning the degree of common variance is said to be middling, and is adequate for the study (Malhotra, 2011). In keeping up with unidimensionality assumption (Lazarsfeld, 1959), EFA ensured that the present study maintains unidimensionality. Accordingly, EFA for BF, EFA for CF, EFA for DF and EFA for IP accounted for 83 percent, 79 percent, 73 percent and 86 percent of the variance, respectively. The Convergent Validity (Campbell \& Fiske, 1959) of the study assessed using Average Variance Extracted (AVE) and Composite Reliability (CR) estimates, revealed that this study holds for convergent validity property as AVE estimate for every variable is more than 0.50 and the CR estimate for every variable is more than 0.70 (Fornell \& Larcker, 1981). To measure the reliability of the study, CA estimate was used. The results showed that all the dimensions/ factors have recorded a CA value of more than 0.90 , which indicates such dimensions/ factors are highly reliable to be adopted in the study (Nunnally, 1978; Shelby, 2011). Table 1 shows a summary of analyses, including descriptive statistics, Cronbach's alpha and convergent validity tests.

Table 1. Multivariate assumptions' tests 


\begin{tabular}{|c|c|c|c|c|c|c|c|}
\hline \multirow{2}{*}{$\begin{array}{l}\text { Factor/ } \\
\text { Dimension }\end{array}$} & \multirow{2}{*}{ Mean } & \multirow{2}{*}{$\begin{array}{l}\text { Standard } \\
\text { deviation }\end{array}$} & \multicolumn{2}{|c|}{ Standardised estimate } & \multirow{2}{*}{$\mathrm{CA}$} & \multirow{2}{*}{ AVE } & \multirow{2}{*}{$\mathrm{CR}$} \\
\hline & & & Minimum & Maximum & & & \\
\hline HT & 3.9516 & 1.1028 & 0.73 & 0.95 & 0.910 & 0.828 & 0.951 \\
\hline PT & 4.5000 & 1.1149 & 0.80 & 1.06 & 0.912 & 0.912 & 0.954 \\
\hline MF & 4.8599 & 0.8909 & 0.81 & 0.99 & 0.935 & 0.865 & 0.928 \\
\hline $\mathrm{CF}$ (SBR) & 3.2129 & 1.1268 & 0.68 & 0.99 & 0.872 & 0.788 & 0.937 \\
\hline $\mathrm{DF}(\mathrm{EK})$ & 3.7885 & 0.8309 & 0.49 & 0.99 & 0.868 & 0.775 & 0.932 \\
\hline IP & 3.2234 & 1.0234 & 0.69 & 1.00 & 0.985 & 0.804 & 0.925 \\
\hline
\end{tabular}

\subsection{The Measurement Model}

The measurement models were constructed for HT - IP, PT - IP, MF - IP, CF (SBR) - IP and DF (EK) - IP relationships, and subsequently tested for validity and reliability. HT, PT and MFs were measured using the 6-point Likert scale developed by Waweru et al. (2008) and adopted from Luong and Ha (2011), while CF (SBR) and DF (EK) were measured using the 5-point Likert scale adopted from Ponnamperuma and Gunatilake (2013). Considering such relationships, factor loadings of all but the item that captures overconfidence bias (OC) under HT were greater than 0.5 , which is acceptable (Hair et al., 2010). Furthermore, all the regression weights were significant at the 0.05 confidence interval. The Goodness of Fit (GOF) indices (CMIN/DF, GFI, AGFI, IFI, TLI, CFI and PRATIO) of HT IP relationship, PT - IP relationship, MF - IP relationship, CF - IP relationship and DF - IP relationship indicated good model fits. Accordingly, the model fit of the measurement models for HT, PT, MFs, CF and DF are established.

\subsection{The Structural Model}

Structural models were developed to test direct as well as moderating effects of the afore-mentioned relationships. All the hypotheses of the present study were tested at the 95 percent confidence level. The GOF indices of HT - IP, PT - IP and MF - IP relationships revealed an adequate model fit while the same for BF manifested a good model fit. Furthermore, the GOF indices of CF - IP and DF - IP relationships showed an adequate model fit for the purpose of the study.

It was hypothesised that heuristics have a significant impact on IP (H1), loss aversion as a cognitive bias under prospect theory has a significant impact on IP (H2), MFs have a significant impact on IP (H3) and BF collectively have a significant positive impact on IP (H4). Furthermore, it was hypothesised that SBR strongly moderates the relationship between HT and IP (H5a), SBR strongly moderates the relationship between MFs and IP (H5b), EK strongly moderates the relationship between HT and IP (H6a) and EK strongly moderates the relationship between MFs and (H6b). The results exposed that MFs have recorded the strongest impact on IP with a standardised coefficient of 0.783 . The second highest impact comes from PT with a coefficient of 0.531 , while the least impact is generated from HT originating from herding behaviour with a coefficient of 0.400 . It was evident that all the above impacts are significant at 99 percent confidence level. Accordingly, as summarized in Table 2, H1, H2 and H3 are established in the study. $\mathrm{H} 4$ of the study is also established as regression estimates show a coefficient of 0.997 at 99 percent confidence level (see Table 2). Results summarised in Table 2 indicate that the moderating impact of SBR is weak and negative on the relationship between HT and IP, with a coefficient of -0.158 , and the moderating impact of SBR is weak and negative and the relationship between MFs and IP as well, with a coefficient of -0.115 . Hence, H5a and $\mathrm{H} 5 \mathrm{~b}$ of the study are established with a high significance level. Moreover, the estimates presented in Table 2 confirm H6a and H6b, where the moderating influence of EK on the relationship between HT and IP recorded a weak negative impact, with a coefficient of -0.194 and the moderating influence of EK on the relationship between MFs and IP recorded a weak negative impact as well, with a coefficient of -0.255 .

Table 2. Summary of hypothesis testing

\begin{tabular}{lllll}
\hline Hypothesis & Path & $\begin{array}{l}\text { Standardised beta } \\
(\mathrm{B})\end{array}$ & $\begin{array}{l}\text { Significance } \\
(\mathrm{P} \text { Value })\end{array}$ & Decision \\
\hline $\mathrm{H}_{1}$ & $\mathrm{HT} \rightarrow \mathrm{IP}$ & 0.400 & 0.000 & Supported \\
$\mathrm{H}_{2}$ & $\mathrm{PT} \rightarrow \mathrm{IP}$ & 0.531 & 0.000 & Supported \\
$\mathrm{H}_{3}$ & $\mathrm{MF} \rightarrow \mathrm{IP}$ & 0.783 & 0.000 & Supported \\
$\mathrm{H}_{4}$ & $\mathrm{BF} \rightarrow \mathrm{IP}$ & 0.997 & 0.000 & Supported \\
\hline
\end{tabular}




\begin{tabular}{lllll}
\hline $\mathrm{H}_{5 \mathrm{a}}$ & $\mathrm{HC} \rightarrow \mathrm{IP}$ & -0.158 & 0.000 & Supported \\
$\mathrm{H}_{5 \mathrm{~b}}$ & $\mathrm{MC} \rightarrow \mathrm{IP}$ & -0.115 & 0.002 & Supported \\
$\mathrm{H}_{6 \mathrm{a}}$ & $\mathrm{HD} \rightarrow \mathrm{IP}$ & -0.194 & 0.000 & Supported \\
$\mathrm{H}_{6 \mathrm{~b}}$ & $\mathrm{MD} \rightarrow \mathrm{IP}$ & -0.255 & 0.000 & Supported \\
\hline
\end{tabular}

\section{Discussion}

Purpose of this study was to empirically examine the behavioural and other biases of individual investors with respect to stock market trading. Data for the study were collected from 221 individual investors who traded on the CSE during the first half of 2019. The first objective of the study was to determine the impact of behavioural factors of individuals on investor's investment performance at the CSE. The findings of the present study reveal that from an individual investor's standpoint, he/she is likely to gain greater financial returns when he/she follows other investors' trading patterns while receiving stock broker's recommendations and trading on existing knowledge on stock market. The presence of herding can be justified as the stock market in Sri Lanka is inefficient, thus supports empirical findings of Fernando and Jayasinghe (2010) as well as conventional finance theories such as Capital Asset Pricing Model, Dividend Discount Model and Markowitz Mean-Variance Portfolio Theory.

In the spectrum of Prospect Theory, the results of the study show that there is a positive relationship between prospect behaviour of individuals and investor's investment performance. Empirical findings of Barberis and Huang (2001), Barberis and Thaler (2003) and Menike et al. (2015) revealed a negative relationship between loss aversion and individual investor's investment performance. In contrast to the negative relationship, the present study found a positive relationship between loss aversion and individual investor's investment performance. This indicates that individual investors are willing to take risks, in other words, to gamble (Tang et al., 2016) in the expectation of higher financial returns, even when they suffer financial losses. The reason why individual investors trading on the CSE gamble on their stock trading could be that the CSE is found to be inefficient as reported in Fernando and Jayasinghe (2010). This paves the way for the investors on the CSE to gamble in the face of such information asymmetries. The finding is further supported by the findings reported in Mellers et al. (1997) where they have concluded that financial gains and losses were rated as roughly equal in intensity. Accordingly, the findings reported in Mellers et al. (1997) and Tang et al. (2016) justify why loss aversion bias showed a negative relationship with individual investor's investment performance. Thereby, this study concludes that individual investors trading on the CSE are willing to gamble even at the expense of suffering financial losses, with the expectation of gaining superior financial returns (the expectation to gain superior financial returns is derived from the CAPM model as posited by Sharpe (1964), Lintner (1965) and Black (1972). According to the results of the present study, there is a positive relationship between market factors and individual investor's investment performance. However, Luong and Ha (2011) reported that market factors do not influence individual investor's investment performance at all.

Among three behavioural factors studied in the paper, the most influential behavioural variables were market information and past trends of stocks. In fact, market information and past trends of stocks were found to show a strong positive relationship with individual investor's investment performance. Furthermore, descriptive statistics on behavioural factors and other factors revealed that investors themselves believed that market factors have the highest impact upon their investment decisions. Therefore, these findings indicate that individual investors trading on the CSE being more mindful about and interested in market information. Furthermore, past trends of stocks than other individual investor's stock trading patterns or the individual investor's own loss aversion behaviour contribute to higher investment performance. These findings support Luong and $\mathrm{Ha}$ (2011), which was conducted on the Vietnamese stock market - the HOSE.

At the same time, findings of the paper contradict the findings reported in Vijaya (2016), which was based on Indian retail equity investors where the study found that market factors have a negative effect on retail investors' investment performance. Moreover, a study done in Sri Lankan context by Kengatharan and Kengatharan (2014) also contradict with the findings of the present study as they found that market information does not affect individual investor's investment performance at the CSE.

The second objective of the study was to examine the extent to which stock broker's recommendation as a contextual factor moderates the relationship between individual investor's behaviour and individual investor's investment performance at the CSE. The analysis of two-way interactions revealed that stock broker's recommendations dampens the positive relationship between heuristics and individual investor's investment performance. This novel finding implies that when individual investors discretely imitate other investors' stock trading behaviour, such acts will bring positive financial returns by way of profits and pay-offs, and if they trade on stock broker's 
recommendations they would end up with lower or even negative financial returns (financial losses). Therefore, the results of this study signify that greater the degree to which individual investors trade on stock broker's recommendations whilst following other investors' trading patterns it is more likely to suffer poor investment performance. Moreover, stock broker's recommendations weakenss the positive relationship between market factors and individual investor's investment performance. Similar to the interaction effect stemming from both stock broker's recommendations and the behaviour of imitating other investors' decisions, stock broker's recommendations are likely to weaken individual investor's investment performance when investors trade on market information and past trends of stocks, simultaneously. This encounter indicates that when individuals are updated with market information and trade on past trends of stocks, they are likely to enjoy optimistic financial returns. However, if such investors follow stock broker's recommendations, they are likely to fall short of their desired investment performance.

Third objective of this study was to scrutinise the extent to which existing knowledge on stock market as a demographic factor moderates the relationship between individual investor's behaviour and individual investor's investment performance at the CSE. According to the two-way interaction analysis, existing knowledge on stock market diminishes the positive relationship between heuristics and individual investor's investment performance. Since authors of this study could not find past scholarly works on this area, this finding would be novel to the behavioural finance literature. The finding implies that when individual investors discretely imitate other investors' investment behaviour, such discrete imitation will bring about positive financial returns in the form of profits and pay-offs. In other words, if such investors trade on existing knowledge on stock market, they end up with inferior financial returns. Therefore, the results obtained in this study signify that greater the degree to which individual investors utilise their own knowledge of the stock market while following other investors' trading behaviour, they are more likely to receive poor financial returns. Likewise, existing knowledge on stock market stifles the positive relationship between market factors and investor's performance. Similar to the interaction effect stemming from both existing knowledge on stock market and herding behaviour, existing knowledge on stock market, as found in this study, is likely to weaken individual investor's investment performance. Furthermore, as per the findings of the current study, this is only true when investors concurrently trade on market information and past trends of stocks as well as on their own knowledge about the share market. This is an indication that when individual investors are updated with market information and trade on past trends of stocks, they are likely to gain positive financial returns. If investors try to capitalise on existing knowledge on stock market and attempt to outperform other investors, they are not likely to meet their desired investment performance. With these findings, the authors of this study report, at least in the Sri Lankan context that possessing greater knowledge of the stock market may not necessarily give individual investors the edge to outperform the stock market and gain greater financial returns. Retail investors were found to exhibit a deficiency in professional skills and knowledge relevant to collecting and managing investment information (Wang, Shi \& Fan, 2006). This would effectively explain why individual investors trading on the CSE, receive inferior returns when they trade on an individual investor's existing knowledge on the stock market.

\subsection{Theoretical Implications}

Findings of this paper induce several theoretical and managerial implications as explained below. Theoretical model adopted in this paper is predominantly governed by behavioural finance theories. As per Sewell (2007), behavioural finance refers to holistic study of the influence of psychology has on the behaviour of finance practitioners and the consequent effect on financial markets. Behavioural finance theories reiterate investment decision making, which tends to be more subjective because it is biased towards mental illusions (Ritter, 2003).

Accordingly, there are various theories that explain the behavioural concept of illogicality. Firstly, the prospect theory clarifies how people frame and value decisions involving uncertainty by looking at choices concerning potential gains or losses in relation to a specific reference point which is more often than not the purchase price (Kahneman \& Tversky, 1979). Secondly, according to Kahneman and Tversky (1974), heuristic theory articulates that individuals have a propensity to make judgments swiftly, and are simplifying strategies used to approach complex problems. Thirdly, as per the findings of Reilly and Brown (2009), the relationship between expected returns and market beta is insignificant, which contradicts the traditional Capital Asset Pricing Model theory. Furthermore, Jagannathan and Wang (1996) stated that actual market prices have always contrasted with any intrinsic price predicted using traditional finance models recommended by orthodox scholars. Thereby, the researchers point out that the market always reflects the behavioural biases of investors, leading to a difference in prices, which stresses the significance of market factors in determining investor behaviour related to investment decision making. Fourthly, according to studies done by Froot et al. (1992), Hirshleifer et al. (1994), Hwang and Salmon (2004), and Hung et al. (2010) irrational herding leads to market inefficiencies, driving asset prices away from their intrinsic 
values, and eventually triggering asset mispricing with regard to investments.

Most significantly, contextual factors (Chandra \& Kumar, 2011; Menike et al., 2015) and demographic factors (Warren et al., 1990; Kabra et al., 2010; Amiri et al., 2011; Ponnamperuma \& Gunatilake, 2013), other than behavioural factors which were incorporated in this study as an attempt to contribute towards a stronger theoretical underpinning were found to influence investor's performance. Accordingly, in contributing further towards the already established theories in behavioural finance, this study found stock broker's recommendations as a contextual factor and existing knowledge on stock market as a demographic factor to negatively, but weakly influence on investor's performance. Further, it was found in this study, that stock broker's recommendations and individual investor's existing knowledge on stock market moderately affected investment decisions taken by individual investors. The authors have not found any extant literature that took into account such factors in testing their impact on individual investor's investment performance. Therefore, the current study provides a better theorisation on behavioural factors.

\subsection{Managerial Implications}

In stating the significance of this study from a managerial standpoint, the outcomes of this study provide insights to individual investors who are trading at the CSE to understand whether there are forces beyond finance fundamentals and if so, to adjust their investment decisions accordingly. The implication from the findings of this study would enable for stock brokerage firms of the CSE to forecast the direction of the stock market as behavioural finance biases may possibly determine market trends to which investors respond. Thereby, stock brokers attached to the CSE could formulate better investment policies and strategies so that they can attract more investors. A study conducted by Ponnamperuma and Gunatilake (2013) offers that the management of the CSE needs to pay attention in developing an effective mechanism to ensure historical share price information is readily available to individual investors. This would lead to less information asymmetries so that investors are able to make decisions that are more effective. Kim and Nofsinger (2008) recommended more behavioural finance research on Asian security markets. Accordingly, this paper attempted to make significant contributions to research firms, stock brokerage firms and many other stakeholders using the data from CSE.

The findings of the present study not only provide insights to investment management companies in the context of stock broker's recommendations, but also provide some insights as follows. Individual investors are highly influenced by changes in market information and past trends of stocks when taking investment decisions and the same factors lead to strong positive contributions to financial returns. Individual investors trading on the CSE react to other investors' investment decisions, and this was found to convert positively into financial returns at moderate level. In addition, loss aversion bias of individual investors was found to be moderately augment with investor's performance, while individual investors consider loss aversion to strongly affect their trading decisions. On the front of individual investor demographics, individual investors trade at the CSE who are financial literate end up with inferior IP. However, the said investors consider such factors to moderately influence their investment decision making process. Accordingly, stock brokers need to understand that the Sri Lankan stock market, at least in certain ways, is biased towards behavioural factors as studied and established in this paper. Hence, the authors of this paper claim that stock brokers should contemplate not only the output of objective finance models when advising investors but also should take into consideration market-wide herding, any possible market manipulations, individual investor's propensity towards being influenced by market information, and knowledge of the stock market in possession of such investors as well.

\subsection{Reflections on Further Research}

Considering inherent limitations of the present study, future research may emphasise the following. In addition to conducting a quantitative analysis on questionnaires, it is advisable to conduct a qualitative research through semi-structured interviews or in-depth-interviews to draw a deeper understanding of the behavioural patterns of individual investors. The paper considered individual investors as the unit of analysis in its attempt to identify and establish the behavioural biases and other factors that may affect individual investor's investment performance. Intrinsically, the present study proposes that scholars apply behavioural finance factors, contextual factors, demographic factors as well as other factors to explore the behavioural and other biases influencing the decisions of institutional and professional investors trading on the CSE. According to Wang et al. (2006), retail investors were found to exhibit a deficiency of professional skills and knowledge relevant to collecting and managing investment information which would effectively explain why individual investors received inferior returns when they traded on existing knowledge on stock market. Necessity to assess the behaviour of professional investors and to identify the influences on their investment performance in the Sri Lankan context can be significant, especially with the support 
of the study conducted by Maditinos et al. (2007). These researchers found that professional investors relied more on fundamental and technical analysis trusting objective and traditional finance models. Therefore, the present paper highlights the need to examine whether such findings are compatible with Sri Lankan context where professional and institutional investors are concerned.

In the present study, the effects of stock broker's recommendations as a contextual factor (Chandra \& Kumar, 2011; Ponnamperuma \& Gunatilake, 2013; Menike et al., 2015) and individual investor's existing knowledge of the stock market as a demographic factor (Warren et al., 1990; Kabra et al., 2010; Amiri et al., 2011; Ponnamperuma \& Gunatilake, 2013) were tested independently, as moderators. Hence, further research may look at whether individual investor's existing knowledge of the stock market has an impact on investor's propensity to obtain recommendations from their stock brokers. The present study also found that individual investor's existing knowledge of the stock market and stock broker's recommendations dampen the relationship between behavioural finance factors and individual investor's investment performance. However, the study did not account for degree of individual investor's existing knowledge of the stock market and to identify whether it has a positive association with degree of stock broker's recommendations received. Hence, we suggest future studies to examine this relationship and to study its impact on individual investor's investment performance.

This paper considered only stock broker's recommendations as a contextual factor. Therefore, we recommend future researchers to conduct supplementary research considering other contextual factors such as personal and financial needs, accounting information, neutral information, and firm image (Nagy \& Obenberger, 1994; Sultana \& Pardhasaradhi, 2012; Obamuyi, 2013) in evaluating their influence as moderators of the relationship between behavioural finance factors and individual investor's investment performance. Similarly, such investigators could study other demographic variables such as age, gender, income and experience (Warren et al., 1990; Kabra et al., 2010; Amiri et al., 2011; Ponnamperuma \& Gunatilake, 2013), to evaluate their impact as moderators of the BF - IP relationship.

\section{Conclusion}

Individual investors trading on the Colombo Stock Exchange (CSE) behave irrationally. This paper attempted to investigate the irrationality by testing whether BF, SBR as a CF, and EK as a DF affect IP. Accordingly, this paper posits that individual investors driven by higher financial returns should understand that they are, at least to some extent, likely to be biased towards certain behavioural finance forces at varying levels. To sum up, when individual investors simultaneously follow other investors and keep track of their trading patterns, follow up to date market information and past trends of stocks as well as keep trading on losing stocks while holding winning stocks, they stand to gain greater financial returns. Conversely, if such individual investors rely entirely on SBR and then trade on them, it is likely that they will end up with inferior financial returns or even financial losses. Similarly, when individual investors attempt to capitalise on EK, they end up with paltry returns or losses, meaning that when individual investors rely on EK to outpace the market, they generally suffer mediocre financial returns or even financial losses. In conclusion, this paper posits that individual investors should pay attention to stock broker's recommendations received, and at the same time utilise existing knowledge more wisely and selectively, because there could possibly be market manipulations in terms of fixing stock prices, and stock brokers are likely to be biased towards rational models when advocating on stock trading.

\section{Acknowledgements}

We humbly take this opportunity to convey our sincere gratitude to Dr. A. K. L. Jayewardene who advised us as appropriate and guided us in the right direction. Similarly, our profound gratitude also goes to Prof. J. A. S. K. Jayakody and Dr. Nilakshi Galahitiyawa for their astute comments and continuous encouragement and assistance especially with data analysis. Sakunthala Durairatnam should also be acknowledged for her support extended in terms of proof reading, formatting and bibliography.

\section{References}

Allen, D.W., \& Evans, A.D. (2005). Bidding and overconfidence in experimenting financial markets. Journal of Behavioral Finance, 6(3), 8-120. https://doi.org/10.1207/s15427579jpfm0603_1

Amiri, S., Razavizade, N., \& Vahidi, G.H. (2011). The effect of the interaction between demographic factors and personality traits and financial behaviour factors in terms of investment decision making. Journal of Applied Science and Agriculture, 8(5), 721-728.

Anderson, A., Henker, J., \& Owen, S. (2005). Limit order trading behaviour and individual investor performance. Journal of Behavioral Finance, 6(2), 71-89. https://doi.org/10.1207/s15427579jpfm0602_3 
Bagozzi, R.P., \& Yi, Y. (1991). Multitraite-multimethod matrices in consumer research. Journal of Consumer Research, 17(4), 426-439. https://doi.org/10.1086/208568

Baker, M., \& Wurgler, J. (2007). Investor sentiment in the stock market. Journal of Economic Perspectives, 21(2), 129-151. https://doi.org/10.1257/jep.21.2.129

Barber, B.M., \& Odean, T. (1999). The courage of misguided convictions: The trading behaviour of individual investors. Financial Analyst Journal, 55(6), 41-55. https://doi.org/10.2469/faj.v55.n6.2313

Barberis, N., \& Huang, M. (2001). Mental accounting, loss aversion, and individual stock returns. The Journal of Finance, 56(4), 1247-1292. https://doi.org/10.1111/0022-1082.00367

Barberis, N., \& Thaler, R. (2003). A survey of behavioural finance. Handbook of the Economics and Finance, 1(2), 1053-1123. https://doi.org/10.1016/S1574-0102(03)01027-6

Black, F. (1972). Capital market equilibrium and restricted borrowing. The Journal of Business, 45(3), 444-455. https://doi.org/10.1086/295472

Bryman, A., \& Bell, E. (2007). Business Research Methods, Oxford University Press, USA.

Chandra, A., \& Kumar, R. (2011). Determinants of individual investor behaviour: An orthogonal linear transformation approach, Available at: https://www.researchgate.net/publication/50514126_Determinants_of_Individual_Investor_Behaviour_An_Orth ogonal_Linear_Transformation_Approach

Chang, S.J., Witteloostuijn, A., \& Eden, L. (2010). From the editors: Common method variance in international business research. Journal of International Business Studies, 41(2), 178-184. https://doi.org/10.1057/jibs.2009.88

Cronbach, L. J. (1946). Response sets and test validity. Educational and Psychological Measurement, 6(4), 475-494. https://doi.org/10.1177/001316444600600405

Croushore, D. (2006). Money and Banking: A Policy Oriented Approach, Cengage Learning.

DeBondt, W.M., \& Thaler, R.H. (1995). Financial decision-making in markets and firms: A behavioural perspective, Handbooks in Operations Research and Management Science, 9(13), 385-410. https://doi.org/10.1016/S0927-0507(05)80057-X

Devenow, A., \& Welch, I. (1996). Rational herding in financial economics. European Economic Review, 40(3-5), 603-615. https://doi.org/10.1016/0014-2921(95)00073-9

Duasa, J., \& Kassim, S. (2009). Herd behaviour in Malaysian capital market: An empirical analysis', Munich Personal RePEc Archive. Available at: http://mpra.ub.uni-muenchen.de/13303/

Eagly, A. H., \& Carli, L.L. (1981). Sex of researchers and sex-typed communication as determinants of sex differences in influenceability. Psychological Bulletin, 90(1), 1-20. https://doi.org/10.1037/0033-2909.90.1.1

Fama, E. F. (1970). Efficient capital markets: A review of theory and empirical work. The Journal of Finance, 25(2), 383-417. https://doi.org/10.1111/j.1540-6261.1970.tb00518.x

Fernando, S., \& Jayasinghe, P. (2010). Evidence for weak form efficiency in stock markets: The Case of Colombo Stock Exchange' (Unpublished thesis)

Filbeck, G., Hatfield, P., \& Horvath, P. (2005). Risk aversion and personality type. Journal of Behavioral Finance, 6(4), 170-180. https://doi.org/10.1207/s15427579jpfm0604_1

Fornell, C., \& Larcker, D. F. (1981). Evaluating structural equation models with unobservable variables and measurement error. Journal of Marketing Research, 18(1), 39-50. https://doi.org/10.1177/002224378101800104

Froot, K. A., Scharfstein, D. S., \& Stein, J.C. (1992). Herd on the street: Informational inefficiencies in a market with short-term speculation. The Journal of Finance, 47(4), 1461-1484. https://doi.org/10.1111/j.1540-6261.1992.tb04665.x

Gervais, S., Simon, H., \& Odean, T. (2001). Learning to be overconfident. The Review of Financial Studies, 14(1), 1-27. https://doi.org/10.1093/rfs/14.1.1

Gordon, M. J. (1959). Dividends, earnings and stock prices. Review of Economics and Statistics, 41(2), 99-105. https://doi.org/10.2307/1927792

Gordon, M. J. (1962). The Investment, Financing, and Valuation of the Corporation, Homewood, IL. 
Gordon, M. J., \& Shapiro, E. (1956). Capital equipment analysis: The required rate of profit. Management Science, 3(1), 102-110. https://doi.org/10.1287/mnsc.3.1.102

Gounaris, K. M., \& Prout, M. F. (2009). Repairing relationships and restoring trust: Behavioural finance and the economic crisis. Journal of Financial Service Professionals, 63(4), 75-84.

Hair Jr, J.F., Black, W.C., Babin, B.J., \& Anderson, R.E. (2010). Multivariate Data Analysis. Pearson Higher Education.

Hirshleifer, D., Subrahmanyam, A., \& Titman, S. (1994). Security analysis and trading patterns when some investors receive information before. The Journal of Finance, 49(5), 1665-1698. https://doi.org/10.1111/j.1540-6261.1994.tb04777.x

Hung, W., Lu, C.C., \& Lee, C. F. (2010). Mutual fund herding its impact on stock returns: Evidence from the Taiwan Stock Market. Pacific-Basin Finance Journal, 18(5), 477-493. https://doi.org/10.1016/j.pacfin.2010.06.001

Hvide, H. K. (2002). Pragmatic beliefs and overconfidence. Journal of Economic Behaviour and Organization, 48(1), 15-28. https://doi.org/10.1016/S0167-2681(01)00221-9

Hwang, S., \& Salmon, M. (2004). Market stress and herding. Journal of Empirical Finance, 11(4), 585-616. https://doi.org/10.1016/j.jempfin.2004.04.003

Jagannathan, R., \& Wang, Z. (1996). The conditional CAPM and the cross-section of expected returns. The Journal of Finance, 51(1), 3-53. https://doi.org/10.1111/j.1540-6261.1996.tb05201.x

Jaswani, T. (2008). Function and purpose of stock market. Article Base, Available at: http://www.articlesbase.com/investing-articles/function-and-purpose-of-stock-market-582881.html.

Kabra, G., Mishra, P. K., \& Dash, M.K. (2010). Factors influencing investment decisions of generations in India: An econometric study. Asian Journal of Management Research, 1(1), 308-328.

Kahneman, D., \& Tversky., A. (1974). Judgment under uncertainty: heuristics and biases. Science, 185(4157), 1124-1131. https://doi.org/10.1126/science.185.4157.1124

Kahneman, D., \& Tversky, A. (1979). Prospect theory: An analysis of decision-making under risk, Econometrica, 47(2), 263-291. https://doi.org/10.2307/1914185

Kengatharan, L., \& Kengatharan, N. (2014). The influence of behavioral factors in making investment decisions and performance: Study on investors of Colombo Stock Exchange, Sri Lanka. Asian Journal of Finance and Accounting, 6(1), 1-23. https://doi.org/10.5296/ajfa.v6i1.4893

Kim, K., \& Nofsinger, J. (2008). Behavioural finance in Asia, Pacific-Basin Finance Journal, 16(1-2), 1-7. https://doi.org/10.1016/j.pacfin.2007.04.001

Kumar, A. \& Lee, C.M. (2006). Retail investor sentiment and return comovements. The Journal of Finance, 61(5), 2451-2486. http://dx.doi.org/10.1111/j.1540-6261.2006.01063.x

Lazarsfeld, P.F. (1959). Latent Structure Analysis. Psychology: A Study of a Science, 3, 476-543.

Lintner, J. (1965). The valuation of risk assets on the selection of risky investments in stock portfolios and capital budgets. Review of Economics and Statistics, 47(1), 13-37. https://doi.org/10.2307/1924119

Lin, H.W. (2011). Does the disposition effect exhibit during financial crisis'? International conference on economics and finance Research 2011proceedings, Singapore, 6-10.

Luong, L.P \& Ha, D.T. (2011). Behavioural factors influencing individual investors' decision making and performance: A survey at the Ho Chi Minh Stock Exchange. Umea School of Business, Umea University: China.

Maditinos, D.I., Sevic, Z., \& Theriou, N.G. (2007). Investors' behaviour in the Athens Stock Exchange (ASE). Studies in Economics and Finance, 34(1), 32-50.

Malhotra, N.K. (2011). Marketing Research: An Applied Orientation. Pearson Prentice Hall, Delhi.

Markowitz, H. M. (1959). Portfolio Selection: Efficient Diversification of Investments. John Wiley and Sons.

Mellers, B.A., Schwartz, A., Ho, K., \& Ritov, I. (1997). Decision affect theory: Emotional reactions to the outcomes of risky options. Psychological Science, 8(6), 423-429. https://doi.org/10.1111/j.1467-9280.1997.tb00455.x

Menike, L.M., Dunusinghe, P. \& Ranasinghe, A. (2015). Behavioural factors influence on investment performance: A 
survey of individual investors at Colombo Stock Exchange. 10th annual London business research conference proceedings, London, 1-17.

Menkhof, L., Schmidt, U., \& Brozynski, T. (2006). The impact of experience on risk taking, overconfidence, and herding of fund managers: Complementary survey evidence. European Economic Review, 50(7), 1753-1766. https://doi.org/10.1016/j.euroecorev.2005.08.001

Nagy, R.A., \& Obenberger, R.W. (1994). Factors influencing individual investor behaviour, Financial Analysts Journal, 50(4), 63-68. https://doi.org/10.2469/faj.v50.n4.63

Nardi, P. M. (2005). Interpreting Data: A Guide to Understanding Research. Pearson, New York.

Nunnally, J.C. (1978). Psychometric Theory. McGraw-Hill, New York.

Obamuyi, T.M. (2013). Factors influencing investment decisions in capital market: A study of individual investors in Nigeria. Organizations and Markets in Emerging Economies, 4(1), 141-161.

Odean, T. (1998). Are investors reluctant to realize their losses? The Journal of Finance, 53(5), 1775-1798. https://doi.org/10.1111/0022-1082.00072

Odean, T. (1999). Do investors trade too much? American Economic Review, 89(5), 1279-1298. https://doi.org/10.1257/aer.89.5.1279

Ponnamperuma, C.J., \& Gunatilake, C. (2013). Factors influencing investor behaviour: The case of Colombo Stock Exchange. University of Sri Jayewardenepura.

Rashid, M., \& Nishat, M. (2009). Satisfaction of the retail investors on the structural efficiency of the market: Evidence from a developing country context. Asian Academy of Management Journal, 14(2), 41-64.

Reilly, F., \& Brown, K. (2009). Investment Analysis and Portfolio Management. South-Western, Ohio.

Ritter, J. R. (2003). Behavioral finance. Pacific-Basin Finance Journal, 11(4), 429-437. https://doi.org/10.1016/S0927-538X(03)00048-9

Rockenbach, B. (2004). The behavioural relevance of mental accounting for the pricing of financial options. Journal of Economic Behavior and Organization, 53(4), 513-527. https://doi.org/10.1016/S0167-2681(03)00097-0

Saunders, M., Lewis, P., \& Thornhill, A. (2009). Research Methods for Business Students. Pearson Education Limited, Italy.

Sewell, M. (2007). Behavioural Finance. University of Cambridge, Available at: http://www.behaviouralfinance.net/behavioural-finance.pdf.

Sewwandi, W. (2016). Herding in Colombo Stock Exchange. EPRA International Journal of Multidisciplinary Research, 2(3), 182-186.

Sharpe, F.W. (1964). Capital asset prices: A theory of market equilibrium under conditions of risk. The Journal of Finance, 19(4), 425-442.

Shefrin, H., \& Statman, M. (1985). The disposition to sell winners too early and ride losers too long: theory and evidence. The Journal of Finance, 40(3), 777-790. https://doi.org/10.2307/2327802

Shelby, L. B. (2011). Beyond Cronbach's alpha: Considering confirmatory factor analysis and segmentation. Human Dimensions of Wildlife, 16(2), 142-148. https://doi.org/10.1080/10871209.2011.537302

Simmons, J., LeBoeuf, R., \& Nelson, L. (2010). The effect of accuracy motivation on anchoring and adjustment: Do people adjust from provided anchors? Journal of Personality and Social Psychology, 99(6), 917-932. http://dx.doi.org/10.1037/a0021540

Spector, P.E. (1987). Method variance as an artefact in self-reported affect and perceptions at work: Myth or significant problem. Journal of Applied Psychology, 72(3), 438-443.

Sultana, S.T. \& Pardhasaradhi, S. (2012). An empirical analysis of factors influencing Indian individual equity investors' decision making and behaviour. European Journal of Business and Management, 4(18), 50-61.

Tang, H., Liang, Z., Zhou, K., Huang, G.H., Rao, L.L., \& Li, S. (2016). Positive and negative affect in loss aversion: Additive or subtractive logic? Journal of Behavioral Decision Making, 29(4), 381-391. https://doi.org/10.1002/bdm.1884

Taylor, S.E., \& Brown, J.D. (1988). Illusion and well-being: A social psychological perspective on mental health, 
Psychological Bulletin, 103(2), 1193-1210. https://doi.org/10.1037/0033-2909.103.2.193

Thaler, R.H. (1999). The end of behavioural finance. Financial Analysts Journal, 55(6), 12-17. https://doi.org/10.2469/faj.v55.n6.2310

Tukey, J.W. (1977). Exploratory Data Analysis. Reading: MA.

Tversky, A., \& Kahneman, D. (1992). Advances in prospect theory: Cumulative representation of uncertainty. Journal of Risk and Uncertainty, 5, 297-323. https://doi.org/10.1007/BF00122574

Vijaya, E. (2016). An empirical analysis on behavioural pattern of Indian retail equity investors. Journal of Resources Development and Management, 16, 103-112.

Wang, X.L., Shi, K., \& Fan, H.X. (2006). Psychological mechanisms of investors in Chinese Stock Markets. Journal of Economic Psychology, 27(6), 762-780. https://doi.org/10.1016/j.joep.2006.06.007

Warren, W.E., Stevens, R.E., \& McConkey, C.W. (1990). Using demographic and lifestyle analysis to segment individual investors. Financial Analysts Journal, 46(2), 74-77.

Waweru, N.M., Munyoki, E., \& Uliana, E. (2008). The effects of behavioural factors in investment decision-making: A survey of institutional investors operating at the Nairobi Stock Rockenbach. International Journal of Business and Emerging Markets, 1(1), 24-41. https://doi.org/10.1504/IJBEM.2008.019243 